\title{
Risk factors for falls with severe fracture in elderly people living in a middle-income country: a case control study Evandro SF Coutinho*1, Astrid Fletcher ${ }^{2}$, Katia V Bloch ${ }^{3}$ and Laura C Rodrigues ${ }^{4}$
}

\begin{abstract}
Address: ${ }^{1}$ Department of Epidemiology, National School of Public Health, Oswaldo Cruz Foundation, Rio de Janeiro, Brazil, ${ }^{2}$ NonCommunicable Disease Epidemiology Unit, Department of Epidemiology and Population Health, London School of Hygiene \& Tropical Medicine, London, UK, ${ }^{3}$ Institute of Studies in Public Health, Federal University of Rio de Janeiro, Rio de Janeiro, Brazil and ${ }^{4}$ Infectious Diseases Epidemiology Unit, Department of Infectious and Tropical Diseases, London School of Hygiene \& Tropical Medicine, London, UK

Email: Evandro SF Coutinho* - esfcoutinho@ensp.fiocruz.br; Astrid Fletcher - Astrid.Fletcher@lshtm.ac.uk; Katia V Bloch - bloch@hucff.ufrj.br; Laura C Rodrigues - Laura.Rodrigues@lshtm.ac.uk

* Corresponding author
\end{abstract}

Published: 26 August 2008

BMC Geriatrics 2008, 8:21 doi:10.1 |86/147|-23|8-8-21
Received: 20 March 2008

Accepted: 26 August 2008

This article is available from: http://www.biomedcentral.com/I47|-23|8/8/2I

(C) 2008 Coutinho et al; licensee BioMed Central Ltd.

This is an Open Access article distributed under the terms of the Creative Commons Attribution License (http://creativecommons.org/licenses/by/2.0), which permits unrestricted use, distribution, and reproduction in any medium, provided the original work is properly cited.

\begin{abstract}
Background: Fracture after falling has been identified as an important problem in public health. Most studies of risk factors for fractures due to falls have been carried out in developed countries, although the size of the elderly population is increasing fast in middle income countries. The objective of this paper is to identify risk factors for fall related to severe fractures in those aged 60 or more in a middle-income country.
\end{abstract}

Methods: A case-control study was carried out in Rio de Janeiro-Brazil based general hospitals between 2002-2003. Two hundred-fifty hospitalised cases of fracture were matched with 250 community controls by sex, age group and living area. Data were collected for socio-demographic variables, health status and drugs used before the fall. A conditional logistic regression model was fitted to identify variables associated with the risk of fall related severe fracture.

Results: Low body mass index, cognitive impairment, stroke and lack of urine control were associated with increased risk of severe fall related fractures. Benzodiazepines and muscle relaxants were also related to an increased risk of severe fractures while moderate use of alcohol was associated with reduced risk.

Conclusion: Although the association between benzodiazepines and fractures due to fall has been consistently demonstrated for old people, this has not been the case for muscle relaxant drugs. The decision to prescribe muscle relaxants for elderly people should take into account the risk of severe fracture associated with these drugs.

\section{Background}

About one third of the population aged 65 or more suffers at least one fall a year, of which 5 to $10 \%$ result in severe injuries [1-4]. More than $90 \%$ of hip fractures are the result of a fall $[5,6]$. Falling and the frequency of falls increases exponentially with age $[1,3-5,7]$. Injuries resulting from falls incur costs for health providers, social services, patients and their families [6-8]. 
An active research agenda exists with a focus on prevention [2]. Cognitive impairment, low body mass index and certain medications such as benzodiazepines have been consistently associated with severe injuries from falls [5,912]. Data on the proportion of fall-related injuries attributable to each of these factors is sparse and it is likely that their relative contribution varies from one setting to another.

Most studies of risk factors for fractures due to falls have been carried out in developed countries, although the size of the elderly population is increasing fast in middle income countries. In Brazil the proportion of people over 60 doubled from $4.1 \%$ in 1940 to $8.6 \%$ in the year 2000 , and it is expected to reach $14 \%$ in 2025 [13-15]. Little is known about the frequency, circumstances, risk factors and consequences of falls in Brazil. Perracini \& Ramos [16] examined risk factors for any kind of fall in a cohort of elderly community residents and Rozenfeld et al [17] did a cross-sectional investigation in a recreational facility for the elderly. Coutinho \& Silva [18] carried out a casecontrol study with hospital controls investigating the association between drugs used in the previous 24 hours and the risk of severe fracture after falling.

We conducted a study to investigate a range of health related factors associated with falls leading to hospitalisation due to fractures among elderly people.

\section{Methods}

\section{Design}

A case-control study was carried out in the city of Rio de Janeiro, Brazil.

\section{Participants}

Two hundred and fifty cases were selected from patients aged 60 or more, admitted to five state hospitals (two are university hospitals and three are funded by the local government) with a severe fracture following a fall, between 2002-2003. A fall was broadly defined as an episode in which a person came to rest on the ground or floor and severe fracture was the one leading to hospital admittance. These hospitals admitted about $50 \%$ of all cases of severe fracture in the people aged 60 or over in Rio de Janeiro and were in different geographic areas of the city. The State Health System in the city covers about $70 \%$ of the adult population.

Two hundred and fifty controls were individually matched for sex, age ( \pm 2 years) and neighborhood (residence of cases and controls in the same block). No elected case refused to participate in the study. Selection of controls was carried out using a systematic procedure starting from the case address, with the direction around the block pre-defined by chance. We did not find more than one eli- gible control per household. Twenty-one people who filled the criteria for being a control did not want to take part in the study and were replaced.

\section{Data collection}

The interviewers visited the hospitals everyday to look for new cases. All individuals aged 60 or more admitted to the hospital to treat a fracture were approached and those reporting a fall as the cause of the injury were asked to participate in the study. Interviews took place at hospital (cases) and home (controls) through standard questionnaires applied by trained interviewers of both sexes. All interviewers had a university degree. The questionnaires consisted of a common set of questions and information was obtained from cases, controls and relatives. These included socio-demographic characteristics, circumstances of the fall, self-reported health status before the fall, information on drug use 24 hours and 15 days before the fall (for cases) or before the home visit (for controls), height, weight, current diseases (self reported) and cognitive impairment (evaluated by an adapted translation of the "Short Care" [19] which was validated in Brazil by Veras et al [20]); and history of falls and fractures in the previous 12 months. The present study used the information of the drugs taken in the previous 24 hours, categorised in 21 groups [see Additional file 1].

\section{Sample size}

Without considering the matching, a sample size of 500 individuals would allow to identify an odds ratio of 2 for an exposure of $13 \%$ among controls (confidence level = 0.95 and power $=0.80$ ).

\section{Statistical analysis}

First, an unadjusted analysis (except for the matching variables) was carried out for all socio-demographic and health related variables using conditional logistic regression. In this level all variables with p-value less than 0.25 were selected for multivariate analysis [21]. Second, a multivariate conditional logistic regression model including those variables was fitted to the data. At this stage, variables with $\mathrm{p}$-value equal or less than 0.05 were maintained in the model. Third, variables with p-value larger than 0.25 in the first stage (univariate analysis) were entered in the model and retained if their p-value were equal or less than 0.05 . This last stage was carried out aiming to reduce the chance of excluding important predictors for severe fall related fractures.

Variations in the magnitude of the odds ratios after removing those variables, and multiplicative interactions between drugs and clinical variables were also investigated. The statistical significance of the interaction terms was investigated comparing the models with and without the interaction term through the likelihood ratio test. 
We used literature-based categories for BMI and cognitive impairment for ease of interpretation.

Complementary analysis comparing means used KruskalWallis test as data were either asymmetrical or variances were not homogeneous.

All interviewed people signed an informed consent term. The study was approved by the ethical committee of the National School of Public Health - Oswaldo Cruz Foundation.

\section{Results}

All 250 cases and 250 controls recruited took part in the study. The interval between the fall and the interview did not exceed 48 hours, although some additional information could have been obtained latter. The great majority were women and about half the individuals were aged between 70-79 years old (Table 1). Due to matching, cases and controls had a similar distribution for age, with mean age for cases 75.5 years old (sd: 8.2 ) and 75.3 years old (sd: 7.7) for controls. Widowhood was the most frequent marital status for both groups, but the proportion of divorced was higher among cases than controls. The large majority of those interviewed were not living alone. More than $40 \%$ did not complete elementary education. Less than $15 \%$ were working before the fall.

Seventy percent of the falls resulting in severe fracture occurred between 6:00 am and 6:00 pm, with a similar proportion in the morning and in the afternoon. Most falls took place at home $(67 \%)$, and this proportion increased with age. The most commonly fractured bone was the femur $(72 \%)$ followed by arm/forearm $(19 \%)$. Two cases had vertebral fracture $(2.7 \%)$ and eleven $(4.4 \%)$ had more than one bone fractured. Ninety nine per cent of the cases had to undergo surgical procedures.

Health related factors with a level of significance less than 0.25 in their univariate association with fracture (matched analysis) are presented in table 2. Increased odds ratios were observed for low BMI, low blood pressure, dizziness, diabetes, cognitive impairment, history of stroke, lack of urine control, poor vision, limit in carrying activities of daily living (ADL), fall in the previous 12 months, use of antidepressants, benzodiazepines, muscle relaxants and cerebral vasodilators while reduced odds ratios were observed for poor health status, regular use of alcohol, calcium supplement and calcium channel blockers. Most benzodiazepines were long acting, and the most frequently prescribed was bromazepan. Almost all prescribed muscle relaxants were carisoprodol.

Osteoporosis, Parkinson disease, epilepsy, high blood pressure, use of angiotensin converting enzyme (ACE) inhibitors, antihistamines, analgesics, antiacids, alpha and beta-adrenergic blockers, nitrates, non steroidal antiinflamatory drugs, digoxin, calcium and vitamin D supplements did not reached the pre-defined level of 0.25 significance [see Additional file 2].

Table I: Distribution of socio-demographic variables among cases $(n=250)$ and controls $(n=250)$.

\begin{tabular}{|c|c|c|}
\hline Variable & Cases n (\%) & Controls n (\%) \\
\hline \multicolumn{3}{|l|}{ Sex } \\
\hline Female & $55(78.0)$ & $55(78.0)$ \\
\hline \multicolumn{3}{|l|}{ Age group (years) } \\
\hline $60-69$ & $59(23.6)$ & $56(22.4)$ \\
\hline $70-79$ & $118(47.2)$ & $127(50.8)$ \\
\hline $80-89$ & $6 \mathrm{I}(24.4)$ & $57(22.8)$ \\
\hline 90 and more & $12(4.8)$ & $10(4.0)$ \\
\hline \multicolumn{3}{|l|}{ Marital status } \\
\hline married & $73(29.2)$ & $82(32.8)$ \\
\hline widowed & $116(46.4)$ & $127(50.8)$ \\
\hline divorced & $23(9.2)$ & $8(3.2)$ \\
\hline never married & $38(15.2)$ & $33(13.2)$ \\
\hline \multicolumn{3}{|l|}{ Living alone } \\
\hline no & $201(80.4)$ & $196(78.4)$ \\
\hline yes & $39(15.6)$ & $47(18.8)$ \\
\hline Institution & $10(4.0)$ & $7(2.8)$ \\
\hline \multicolumn{3}{|l|}{ Educational level } \\
\hline none + elementary incomplete elementary & $104(4 \mid .6)$ & $110(44.0)$ \\
\hline level one (about 5 years) & $83(33.2)$ & $84(33.6)$ \\
\hline .level two (about 4 years) & $37(14.8)$ & $30(12.0)$ \\
\hline secondary (about 3 years) & $20(8.0)$ & $15(6.0)$ \\
\hline university & $6(2.4)$ & II (4.4) \\
\hline \multicolumn{3}{|l|}{ Working before the fall } \\
\hline Yes & $34(13.6)$ & $28(\mid I .2)$ \\
\hline
\end{tabular}


Table 2: Distribution of health related variables' among cases and controls, odds ratios ${ }^{2}(\mathrm{OR}), 95 \%$ confidence intervals $(\mathrm{Cl})$ and $\mathrm{p}-$ values $($ cases $=250$, controls $=250)$.

\begin{tabular}{|c|c|c|c|c|}
\hline Variables & Cases n (\%) & Controls n (\%) & OR $(95 \% \mathrm{Cl})$ & $P$ valuel \\
\hline \multicolumn{5}{|l|}{$\mathrm{BMI}-\mathrm{kg} / \mathrm{m}^{2}$} \\
\hline 25 or more & $85(34.1)$ & 118 (47.2) & reference & $<0.01$ \\
\hline $20-24.9$ & $107(43.0)$ & $104(41.6)$ & $1.23(0.72-2.11)$ & \\
\hline less than 20 & $57(22.9)$ & $28(11.2)$ & $3.31(1.49-7.37)$ & \\
\hline \multicolumn{5}{|l|}{ Health status } \\
\hline excellent & $27(10.8)$ & $43(17.2)$ & reference & 0.01 \\
\hline good & $|2|(48.4)$ & $126(50.4)$ & $1.79(0.85-3.76)$ & \\
\hline fair & $90(36.0)$ & $61(24.4)$ & I.82(0.76-4.37) & \\
\hline poor & $12(4.8)$ & $20(8.0)$ & $0.31(0.08-1.27)$ & \\
\hline Dizziness & $70(28.0)$ & $57(22.8)$ & $1.33(0.60-2.21)$ & 0.17 \\
\hline Low blood pressure & $15(6.0)$ & $3(1.2)$ & $5.00(1.45-17.27)$ & 0.01 \\
\hline Diabetes & $52(20.8)$ & $39(15.6)$ & $1.42(0.90-2.25)$ & 0.14 \\
\hline Cognitive impairment ${ }^{3}$ & $64(28.7)$ & $27(10.8)$ & $3.64(2.02-6.58)$ & $<0.01$ \\
\hline Stroke & $28(11.2)$ & $8(3.2)$ & $4.33(1.78-10.53)$ & $<0.01$ \\
\hline Lack of urine control & $69(27.6)$ & $30(12.0)$ & $3.05(1.82-5.12)$ & $<0.01$ \\
\hline Poor vision ${ }^{4}$ & $21(8.8)$ & $9(3.6)$ & $2.63(1.16-5.88)$ & 0.02 \\
\hline Limited in carrying $\mathrm{ADL}^{5}$ & $146(58.4)$ & $113(45.2)$ & $1.85(1.24-2.70)$ & $<0.01$ \\
\hline \multicolumn{5}{|l|}{ Current use of alcohol } \\
\hline not used & $198(79.2)$ & $161(64.4)$ & reference & $<0.01$ \\
\hline less than once a week & $35(14.0)$ & $44(17.6)$ & $0.79(0.40-1.55)$ & \\
\hline at least once a week & $17(6.8)$ & $45(18.0)$ & $0.42(0.17-1.02)$ & \\
\hline Fall in the previous 12 months & $94(37.8)$ & $79(31.6)$ & $1.34(0.91-1.98)$ & 0.14 \\
\hline Antidepressant ${ }^{6}$ & $8(3.2)$ & $3(1.2)$ & $2.67(0.7 \mathrm{I}-10.05)$ & 0.15 \\
\hline Benzodiazepine $^{6}$ & $44(17.6)$ & $19(7.6)$ & $2.56(1.44-4.57)$ & $<0.01$ \\
\hline Ca channel blocker ${ }^{5}$ & $22(8.8)$ & $41(16.4)$ & $0.47(0.27-0.84)$ & 0.01 \\
\hline Ca supplement & $5(2.0 \%)$ & $12(4.8)$ & $0.42(0.15-1.18)$ & 0.10 \\
\hline Diuretics 6 & $35(14.0)$ & $48(19.2)$ & $0.68(0.42-1.10)$ & 0.12 \\
\hline Muscle relaxant ${ }^{6}$ & $21(8.4)$ & $8(3.2)$ & $5.33(1.55-18.30)$ & $<0.01$ \\
\hline Cerebral Vasodilators $^{6}$ & $27(10.8)$ & $14(5.6)$ & $2.08(1.05-4.15)$ & 0.04 \\
\hline
\end{tabular}

I. Selection criteria for this table was univariate $p$-value $<0.25$. P-values for the $2 \times n$ comparisons

2. matched by sex, age group and neighbourhood. OR estimated using conditional logistic regression

3. adapted translation of the "Short Care"

4. unable to identify someone at the opposite side of the room

5. unable to perform at least one of the following activities on his(her) own: use of public transport, drive, walk short distances, eat own meals,

dress up, take medication, comb, go up and downstairs, take shower, cut nails, control urine.

6. in the previous 24 hours

The average total number of drugs were $2.2(\mathrm{sd}=1.47)$ in cases and 2.1 ( $\mathrm{sd}=1.48$ ) among the controls. The difference was not statistically significant $(\mathrm{p}=0.43)$.

When variables presented in table 2 were entered in a multivariate conditional logistic model, diabetes, high blood pressure, rheumatism, poor vision and use of diuretics had significance levels over 0.05 and were dropped from the multivariate model. Table 3 presents the final model. Body mass index equal or less than $20 \mathrm{~kg} / \mathrm{m} 2$, cognitive impairment, previous stroke and lack of urine control were associated with increased incidence of severe fall related fractures while use of alcohol at least once a week was associated with reduced incidence. Concerning the use of drugs in the previous 24 hours, benzodiazepines and muscle relaxants were related to an increased risk of severe fractures while calcium channel blockers were associated with a reduced risk. The highest odds ratio (approximately 5 fold) was observed for use of muscle relaxants and history of stroke, although confidence intervals were large. No effect modification was observed for the variables included in the final model.

\section{Discussion}

Most of the cases of severe fracture due to falling in the present study were female. Most fell at home between 6:00 am and 6:00 pm and the great majority of the fractures affected the femur and the arm/forearm. Risk factors identified were low body index mass, cognitive impair- 
Table 3: Association of health related variables and severe fall related fractures. Adjusted' odds ratios (OR), $95 \%$ confidence intervals $(\mathrm{Cl})$ and $\mathrm{p}$-values (cases $=250$, controls $=250$ )

\begin{tabular}{lcc}
\hline Variables & OR $(95 \% \mathrm{Cl})$ & $\mathrm{P}$ value \\
\hline BMI & reference & \\
25 or more & $1.18(0.71-1.96)$ & 0.63 \\
$20-24.9$ & $3.43(1.64-7.17)$ & $<0.01$ \\
less than 20 & $2.19(1.09-4.41)$ & 0.03 \\
Cognitive impairment & $5.27(1.31-21.20)$ & 0.02 \\
Stroke & $3.16(1.42-7.03)$ & $<0.01$ \\
Lack of urine control & & \\
Current use of alcohol & reference & \\
not used & $0.71(0.38-1.33)$ & 0.29 \\
less than once a week & $0.40(0.18-0.89)$ & 0.02 \\
at least once a week & $2.22(1.07-4.58)$ & 0.03 \\
Benzodiazepine & $0.40(0.19-0.86)$ & 0.02 \\
Ca channel blocker & $4.42(1.02-19.21)$ & 0.04 \\
Muscle relaxant & & \\
\hline
\end{tabular}

I. Each variable is controlled for the other ones in the table plus selfreported health status and activities in daily living using conditional logistic regression.

2. P-values for each variable category compared to the reference level.

Model fit statistics: McFadden's $\mathrm{R}^{2}=0.297$, McFadden's Adj $\mathrm{R}^{2}=$ 0.206 , Count $R^{2}=0.777$, Likelihood-ratio $\chi_{(14 \mathrm{df})}=91.485, \mathrm{p}<0.00 \mathrm{I}$

ment, stroke, lack of urine control, use of benzodiazepine and muscle relaxants.

Our study in a middle-income country setting agrees with some previously reported associations with fracture due to fall observed in developed countries: low body index mass $[9,22,23]$, cognitive impairment [5,22], stroke $[9,10]$, lack of urine control [24-26].

In the present study regular users of alcohol ("at least once a week") were at a reduced risk of severe fractures. Findings for alcohol have not been consistent. Peel et al [27] found a reduced risk of fall-related fracture for moderate alcohol intake while other authors have found the reverse: higher risk of falls leading to fracture associated with higher use of alcohol $[10,28]$. "J" shape patterns in alcohol use have been observed for outcomes such as cardiovascular disease, with non drinkers or those with very low intakes having higher risks compared to those with mild or moderate drinking patterns. In our study, those who reported using alcohol at least once a week rarely made use of alcohol more than twice a week. It is possible that people drinking at least once a week were healthier than those not drinking. Although we attempted to control for this by the inclusion of other health related variables in the model, we cannot exclude the possibility of residual confounding.

As in our investigation, previous studies have identified an effect of benzodiazepines on the risk of fall-related fractures [12]. Hartikainen et al [29] carried out a systematic review of 29 studies that reported the association between the use of medicines and the risk of falls or fallrelated fractures among people aged 60 or more. Nine of them were case-control studies matched by sex and age like our investigation. The authors concluded that central nervous system drugs, mainly psychotropic drugs, were associated with an increased risk of these accidents,

Many drugs commonly used by elderly people have not been systematically studied as risk factor for falls [29]. An important and novel result from our study was the association between the use of muscle relaxants in the last 24 hours and severe fracture due to falling. The odds ratio was very high $(\mathrm{OR}=4.42)$ although the $95 \%$ confidence interval was wide (1.02-19.21). To the best of our knowledge, there is only one study that reported this empirical association among the elderly. French et al [30] used database information to investigate the relationship between registered primary diagnosis of fracture and previous use of some drugs. The authors found that those registered with fracture were prescribed muscle relaxants 1.4 times more than controls (those with non-specific chest pain). This value is much lower than the one we found, but it is difficult to compare these findings as the study designs were quite different.

That muscle relaxants can cause falls is biologically plausible: these drugs are recognized to cause weakness, drowsiness, sedation and anticholinergic effects [31]. Data on the use of muscle relaxants by elderly people, especially for extended periods, are limited but such studies that have been done reported usage by: $3 \%$ of the 60 and over population in Rio de Janeiro-Brazil [32], $0.77 \%$ of the 60 and over population in the USA [33], and $1.2 \%$ of the 75 and over age group in Finland [34]. Although muscle relaxants are recommended for short-term treatment of back pain, Dillon et al [33] reported a mean length of use of 2.1 years in the USA; $44.5 \%$ of users referred use for more than a year. Although it is generally acknowledged that the use of muscle relaxant may be inappropriate and hazardous in the elderly [31,35], the figures quoted above show that their use and their long term use remains a problem. It is likely that usage figures will be higher in places where there is easy access to medications over the counter, commonly in low and medium income countries such as Brazil. The 2002 criteria for potentially inappropriate medication use in older adults [31] does not mention explicitly the risk of falling and suffering a fracture in its evaluation of miorelaxants; the only group of drugs for which concern with falls is mentioned is long acting benzodiazepines

In contrast to previous studies we did not find a significant association between visual impairment $[9,16,36,37]$ 
and diabetes $[28,38]$ with fall related fracture. We did not measure visual acuity but relied on self report and there may have been under-reporting leading to dilution of effect. In the case of diabetes, finding an association with falling may be influenced by the proportion of those with neurological and foot problems. Ottenbacher et al [38] found that the association between diabetes and hip fracture particularly for those taking insulin.

Our study showed an unexpected inverse association between the use of calcium channel blockers (CCB) and the occurrence of severe fall related fracture. Two systematic reviews $[29,39]$ did not find any association between these variables. We cannot exclude the possibility that this finding was due to residual confounding of self-reported health status. CCB and angiotensin converting enzyme inhibitors (ACEI) were the most reported antihypertensives. Although the proportion of controls taking CCB and ACE was the same (16\%), the average total number of drugs referred by the first group was 3.0 while by the second group it was $3.5(\mathrm{p}=0.02)$. This suggests that users of CCB could be healthier than those to which ACEI were prescribed.

The study had some limitations. Most variables were self reported and, in some of the interviews, information was provided or added by relatives that were in the hospital (for cases) or at home (for controls). This could lead to an unknown degree of misclassification of exposures. Moreover, cognitive impairment was evaluated after the fall, and we cannot be sure about the influence of the accident on mental state.

On the other hand, our study has some strengths. There were no refuses among cases and only few among controls and ascertainment of cases was likely to be high as severe fracture will be hospitalised. Controls were selected from same population as cases. Moreover, the study was done in a low income population from a middle-income country, a setting rarely reported for studies on fall related fractures

\section{Conclusion}

What causes falls and fractures in the elderly is an important question as the size of the elderly population is increasing fast in middle income countries. Our study identifies some similar factors and a few differences, including an important role for miorelaxant drugs which are prescribed over the counter in many countries. We studied fractures leading to hospitalisation and it is possible that muscle relaxants are also associated with less severe falls. Urgent and immediate attention is necessary to confirm and quantify the risks as to inform increased control of these drugs in elderly people.

\section{Competing interests}

The authors declare that they have no competing interests.

\section{Authors' contributions}

ESFC had full access to all of the data in the study and takes responsibility for the integrity of the data and the accuracy of the data analysis. Study concept and design: ESFC, LCR and AF. Acquisition of data: ESFC. Analysis and interpretation of data: ESFC, LCR and AF. Drafting the manuscript: ESFC, LCR, AF and KVB. Statistical analysis: ESFC and LCR. Study supervision: ESFC. All authors read and approved the manuscript.

\section{Additional material}

\section{Additional file 1}

Categories and ATC codes for the drugs used in the last 24 hours. The table provided presents the Anatomical Therapeutic Chemical Code for the drugs investigated.

Click here for file

[http://www.biomedcentral.com/content/supplementary/14712318-8-21-S1.doc]

\section{Additional file 2}

Variables with p-value greater than 0.25 (univariate analysis). The table provided presents the odds ratios and $95 \%$ confidence intervals for the variables that did not reach statistical criteria in the preliminary analysis for inclusion in the multivariate analysis.

Click here for file

[http://www.biomedcentral.com/content/supplementary/14712318-8-21-S2.doc]

\section{Acknowledgements}

The Wellcome Trust supported field work (data collection), equipment and travelling costs. The CNPq (Brazilian Research Council) provided scholarship, material and consumables.

We thank Sidney Dutra da Silva, Luana Silva Garcez de Mendonça, Rosania Silva Garcez de Mendonça, Valdir Alvarenga for collecting data for this study.

\section{References}

I. Ryynänen OP, Kivelä SL, Honkanen R, Laippala P, Soini P: Incidence of falling injuries leading to medical treatment in the elderly. Public Health 1991, 105:373-386.

2. Talbot LA, Musiol RJ, Witham EK, Metter EJ: Falls in young, middle-aged and older community dwelling adults: perceived cause, environmental factors and injury. BMC Public Health 2005, 5:86.

3. Masud T, Morris RO: Epidemiology of falls. Age Ageing 200I, 30(Suppl 4):3-7.

4. Francis RM: Falls and fractures. Age Ageing 200I, 30(Suppl 4):25-28.

5. Guo Z, Wills P, Viitanen M, Fastbom J, Winblad B: Cognitive impairment, drug use and the risk of hip fracture in persons over $\mathbf{7 5}$ years old: a community-based prospective study. Am J Epidemiol 1998, I 48:887-892.

6. Woolf $A D$, Akesson K: Preventing fractures in elderly people. BMJ 2004, 327:89-95. 
7. Sattin RW: Falls among older people: a public health perspective. Annu Rev of Publ Health 1992, 13:489-508.

8. Panneman MJ, Goettsch WG, Kramarz P, Herings RM: The costs of benzodiazepine-associated hospital-treated fall injuries in the EU: a Pharmo study. Drugs Aging 2003, 20:833-839.

9. Grisso JA, Kelsey JL, Strom BL, Chiu GY, Maislin G, O'Brien LA, Hoffman S, Kaplan F: Risk factors for falls as a cause of hip fracture in women. The Northeast Hip Fracture Study Group. N Engl J Med 1991, 324:|326-|33|.

10. Grisso JA, Kelsey JL, Strom BL, O'Brien LA, Maislin G, LaPann K, Samelson L, Hoffman S: Risk factors for hip fracture in black women. The Northeast Hip Fracture Study Group. N Engl Med 1994, 330: 1555-1559.

II. Cumming RG, Nevitt MC, Cummings SR: Epidemiology of hip fractures. Epidemiol Rev 1997, 19:244-257.

12. Cumming RG, Le Couteur DG: Benzodiazepines and risk of hip fractures in older people: a review of the evidence. CNS Drugs 2003, 1 7:825-837.

13. Monteiro MFG, Alves MIC: Aspectos demográficos da população idosa no Brasil. In Veras RP: Terceira Idade: um envelhecimento digno para o cidadão do futuro Rio de Janeiro: Relume/Dumará; 1995.

14. Carvalho JA, Garcia RA: The aging process in the Brazilian population: a demographic approach. Cad Saude Publica 2003, 19:725-733.

15. IBGE-Instituto Brasileiro de Geografia e Estatística [http:// www.ibge.gov.br/home/estatistica/populacao/censo2000/ tabelabrasill I I.shtm]. Accessed November 5, 2004

16. Perracini MR, Ramos LR: Fall-related factors in a cohort of elderly community residents. Rev Saude Publica 2002, 36:709-7I6.

17. Rozenfeld S, Camacho LAB, Veras RP: Medication as a risk factor for falls in older women in Brazil. Rev Panam Salud Publica 2003, 13:369-375

18. Coutinho ESF, Silva SD: Medication as a risk factor for falls resulting in severe fractures in the elderly. Cad Saude Publica 2002, 18:1359-1366

19. Gurland B, Golden RR, Teresi JA, Challop J: The Short-Care: an efficient instrument for the assessment of depression, dementia and disability. J Gerontol 1984, 39:166-169.

20. Veras RP, Coutinho E, Ney G Jr: The elderly population of Rio de Janeiro (Brazil): pilot-study as to the trustworthiness and validity of the mental health segment of the BOAS questionnaire. Rev Saude Publica 1990, 24:156-163.

21. Mickey RM, Greenland S: The impact of counfounder selection criteria on effect estimation. Am J Epidemiol 1989, I 29: I 25- I 37.

22. Tinetti ME, Doucette JT, Claus EB: The contribution of predisposing and situational risk factors to serious fall injuries. $J \mathrm{Am}$ Geriatr Soc 1995, 43:1207-1213.

23. Keegan THM, Kelsey JL, King AC, Quesenberry CP Jr, Sidney S: Characteristics of fallers who fracture at the foot, distal forearm, proximal humerus, pelvis, and shaft of the tibia/fibula compared with fallers who do not fracture. Am J Epidemio 2004, I 59:192-203.

24. Wilkins K: Medications and fall related fractures in the elderly. Health Rep 1999, I I:45-53.

25. Kron M, Loy S, Sturn E, Nikolaus T, Becker C: Risk indicators for falls in institutionalized frail elderly. Am J Epidemiol 2003, I 58:645-653.

26. Oliver D, Daly F, Finbarr MC, McMurdo MET: Risk factors and risk assessment tools for falls in hospital in-patients: a systematic review. Age Aging 2004, 33:122-130.

27. Peel NM, McClure RJ, Hendriks JK: Health-protective behaviours and risk of fall-related hip fractures: a population-based casecontrol study. Age Aging 2006, 35:49I-497.

28. Malmivaara A, Heliövaara M, Knekt P, Reunanen A, Aromaa A: Risk factors for injurious fall leading to hospitalization or death in a cohort of 19,500 adults. Am J Epidemiol 1993, 138:384-394.

29. Hartikainen S, Lönnroos E, Louhivuori K: Medication as a risk factor for falls: critical systematic review. J Gerontol A Biol Sci Med Sci 2007, 62(1 0): ||72-|| |81.

30. French DD, Campbel R, Spehar A, Rubenstein LZ, Branch LG, Cunningham F: National outpatient medication profiling: medications associated with outpatient fractures in communitydwelling elderly veterans. Br J Clin Pharmacol 2007, 63:238-244.

31. Flick DM, Cooper JW, Wade WE, Waller JL, Maclean JR, Beers MH: Updating the Beers criteria for potentially Inappropriate
Medication use in older adults. Results of a US consensus panel of experts. Arch Intern Med 2003, 163:2716-2724.

32. Acurcio FA, Rozenfeld S, Klein CH: Perfil de utilização de medicamentos por aposentados brasileiros [Drug use profile among retired Brazilian people]. 2003. (research report)

33. Dillon C, Paulose-Ram R, Hirsch R, Gu Q: Skeletal muscle relaxant use in the United States. Data from the Third National Health and Nutrition Examination Survey (NHANES III). Spine 2004, 8:892-896.

34. Pitkala KH, Strandberg TE, Tilvis RS: Inappropriate drug prescribing in home-dwelling, elderly patients: a population-based survey. Arch Intern Med 2002, 162:1707-1712.

35. Beers $\mathrm{MH}$ : Explicit criteria for determining potentially inappropriate medication use by the elderly. An update. Arch Intern Med 1997, 157:1531-1536.

36. Dargent-Molina P, Favier F, Grandjean H, Baudoin C, Schott AM, Hausherr E, Meunier PJ, Bréart G: Fall-related factors and risk of hip fracture: the EPIDOS prospective study. Lancet 1996, 348: $145-149$

37. Ivers RQ, Norton R, Cumming RG, Butler M, Campbell AJ: Visual impairment and risk of hip fracture. Am J epidemiol 2000, 152:633-639.

38. Ottenbacher KJ, Ostir GV, Peek MK, Goodwin JS, Markides KS: Diabetes mellitus as a rik factor for hip fracture in mexican american older adults. J Gerontol A Biol Sci Med Sci 2002, 57:M648-653.

39. Leipzig RM, Cumming RG, Tinetti ME: Drugs and falls in older people: a systematic review and meta-analysis: II. Cardiac and analgesic drugs. J Am Geriatr Soc 1999, 47:40-50.

\section{Pre-publication history}

The pre-publication history for this paper can be accessed here:

http://www.biomedcentral.com/1471-2318/8/21/prepub

Publish with BioMed Central and every scientist can read your work free of charge

"BioMed Central will be the most significant development for disseminating the results of biomedical research in our lifetime. "

Sir Paul Nurse, Cancer Research UK

Your research papers will be:

- available free of charge to the entire biomedical community

- peer reviewed and published immediately upon acceptance

- cited in PubMed and archived on PubMed Central

- yours - you keep the copyright 